impression that multiple metastases are more readily shown by scanning than by pneumography or angiography. Single metastases are often revealed by these latter methods, but second or third ones are not often shown.

While it is possible to predict the pathology of a certain number of lesions by studying the topography, this is by no means always so. Planiol (1963) uses an entirely different technique by means of which she is able to make a specific diagnosis in a much higher percentage of cases. Her method depends upon the change in count rate at fixed points on the skull at intervals of 2, 24, and 48 hours after an intravenous injection of radioiodinated human serum albumin. She has shown that meningiomas take up the isotope early and metastases late, while the astrocytomas take it up at an intermediate point in time. Since Planiol's method is based purely on count figures, there is no topographical representation of the tumours. Thus it is not possible by her technique to demonstrate, for example, an astrocytoma invading the corpus callosum. However, in her series she was able to diagnose correctly $92 \%$ (175 out of 190) meningiomas, $93 \%$ (292 out of 315 ) glioblastomas, $56 \%$ (48 out of 85 ) astrocytomas (corresponding to our grade I and grade II astrocytomas), and $90 \%$ (216 out of 240) metastases.

The most reliable diagnosis of all in her series was related to abscess, where the accuracy was $100 \%$ (18 out of 18 ). In our single case the abscess was certainly very clearly defined (Case 46).

It would seem that the best exploitation of the injected isotope would be derived from a combination of photoscanning with Planiol's technique. It is our intention to pursue this in the near future.

\section{Summary}

The results of 100 brain scans are described. All the scans were made with ${ }^{203} \mathrm{Hg}$ chlormerodrin using a standard technique. There was no selection of cases referred by neurologists and neurosurgeons, except that patients under the age of 18 were excluded.

There were 53 positive scans, and all these patients appeared to have lesions, though not all these were confirmed histologically. There were 42 negative scans. Of these, 22 were probably truly negative. The remaining 20 were proved to be false-that is, these patients harboured tumours not demonstrated by the method. The causes of the false negatives are discussed and their reduced number in the future is foreshadowed.

There were five equivocal scans. These showed some departure from the normal, but the appearances were not sufficiently clear-cut for definite diagnosis.

Since a positive scan always denotes a lesion and the scanning process is painless and free from risk, it seems that, ideally, this investigation should be made before angiography and/or pneumography. But a negative scan in the face of positive clinical evidence of a mass always requires further investigation.

The method is particularly valuable in the investigation of out-patients and of patients whose clinical picture hardly justifies submission to the more traumatic procedures which also carry some morbidity.

Scanning has been a great help in the diagnosis of metastases, because the older-established neuroradiological procedures tend to show only the larger ones. The results in these cases suggest that secondary deposits in the brain are more often multiple than was previously suggested by classical neuroradiological investigation, although well known by pathologists.

Location of brain tumours by modern scanning techniques is accurate. In some cases the contour and topography allow a precise pathological diagnosis to be made. Unfortunately this is by no means always so, but it is hoped that still greater accuracy will be achieved by refining the technique.

Isotope encephalography has clearly earned its place alongside other neuroradiological contrast methods of investigation.

REFERENCES

Blau, M., and Bender, M. A. (1962). F. nucl. Med., 3, 83. Brinkman, C. A., Wegst, A. V., and Kahn, E. A. (1962). F. Neurosurg, 19,644 .

Bull, J. W. D., and Rovit, R. L. (1957). F. Fac. Radiol. (Lond.), 8, 147. Di Chiro, G. (1961). Acta radiol. (Stockh.), Suppl. No. 201.

Kernohan, J. W., Mabon, R. F., Svien, H. J., and Adson, A. W. (1949). Proc. Mayo Clin., 24, 71 .

Marryat, J., and Bull, J. W. D. (1964). Brit. F. Radiol., 37, 711.

Millikan, C. H., and Sayre, G. P. (1964). Proc. Mayo Clin., 39, 380. Moore, G. E. (1947). Science, 106, 130.

Moore, G. E. (1947), Science,

Pitlyk, P. J., Tauxe, W. N., Kerr, F. W. L., Sedlack, R. E., and Svien, H. J. (1963). Arch. Neurol. (Chic.), 9, 437. Planiol, Th. (1963). Rev. Prat. (Paris), 13, 3625.

\title{
Iron Deficiency and its Relation to Folic-acid Status in Pregnancy : Results of a Clinical Trial
}

\author{
I. CHANARIN,* M.D., D.C.P. ; DOREEN ROTHMAN, $\dagger$ M.R.C.o.G. ; VALERIE BERRY*
}

Brit. med. F., 1965, 1, 480-485

The application of newer methods to the detection of vitamin $B_{12}$ and folic-acid deficiencies has clarified many problems in patients with megaloblastic anaemia, and we have a clearer understanding of these problems than was the case 10 years ago. The situation is less satisfactory, however, in megaloblastic anaemia in pregnancy. Diagnostic criteria are uncertain and the apparent incidence varies in different hospi-

- Medical Research Council Experimental Haematology Research Unit and Department of Haematology, Wright-Fleming Institute of Microbiology, St. Mary's Hospital Medical School, London.

† Department of Obstetrics and Gynaecology, St. Mary's Hospital Medical School, London. tals, from being so low that the condition is regarded as a rarity (Clark, 1952) to being so common that it is diagnosed in 1 in 25 of all pregnant subjects (Hourihane, Coyle, and Drury, 1960). Divergent views have been expressed about the value of the newer tests for folic-acid deficiency (Chanarin, Rothman, and Watson-Williams, 1963 ; Hibbard and Hibbard, 1963 ; Ball and Giles, 1964; Hansen, 1964), and there is disagreement both about the wisdom of folic-acid supplements in pregnancy (Varadi, 1964 ; Forshaw, Moorhouse, and Harwood, 1964) and about how large this supplement should be.

The purpose of this paper is to report some of the results of a clinical trial in pregnancy wherein normal pregnant women 
were allocated at random to one of three groups receiving throughout pregnancy tablets containing an iron preparation, or iron with added folic acid, or simply lactose. In addition to the usual clinical and haematological observations made throughout pregnancy the serum Lactobacillus casei (folate) levels, the urinary formiminoglutamic acid (Figlu) excretion, and the proportion of hypersegmented neutrophils in the stained blood films were noted. It was hoped in this way to investigate, first, the effect of iron deficiency, and, second, the effect of a small folic-acid supplement which was physiological in amount on the incidence of megaloblastic anaemia. The study was also designed to obtain further information about the most helpful methods of establishing a diagnosis of megaloblastic anaemia in pregnancy; and in particular to determine the value of newer tests such as the assay of serum $L$. casei activity and urinary Figlu excretion. We report here the overall results and conclusions of this study. A more detailed study of subjects who developed a megaloblastic form of haemopoiesis while under observation will be reported later.

\section{Methods}

Assay of Serum L. casei (Folate) Activity.-Six serum samples were taken from each subject throughout pregnancy and the puerperium, and these were stored at $-20^{\circ} \mathrm{C}$. and finally assayed together. Dry ascorbate $(10-20 \mathrm{mg} . / \mathrm{ml}$. serum) was added to all sera before storage to prevent deterioration of the $L$. casei active factors (Waters and Mollin, 1961). Preliminary observations showed that there was little deterioration in sera stored for six months under these conditions (Chanarin and Berry, 1964). The assay was carried out as described by Toepfer, Zook, Orr, and Richardson (1951) and Baker, Herbert, Frank, Pasher, Hutner, Wasserman, and Sobotka (1959). The serum was prepared for assay as described by Chanarin and Berry (1964).

Urinary Figlu Excretion.-Urine was collected for eight hours into a container to which had been added $2-3 \mathrm{ml}$. of $\mathrm{N} / \mathrm{HCl}$ after an oral dose of $15 \mathrm{~g}$. of histidine monohydrochloride. The urinary excretion of histidine derivatives was assayed by the method of Chanarin and Bennett (1962).

\section{Haematological Methods}

The haemoglobin concentration and packed-cell volume were estimated from venous blood samples. The cyanmethaemoglobin method was used for haemoglobin estimation and the microhaematocrit for estimation of packed-cell volume.

A count was made of the number of nuclear lobes of the neutrophil polymorph leucocytes. Using a wide-field eyepiece $(\times 6)$ and fluoride objective $(\times 50)$ the number of nuclear lobes in 50 cells was noted and the result expressed as the average number of nuclear lobes per cell (average lobe index). A further 150 cells were scanned and the total number of cells having five or more nuclear lobes was recorded and expressed as a percentage of the 200 cells observed. A nuclear structure was regarded as a separate lobe if it appeared to be clearly separate from the other lobes or if it was connected by a fine (but not coarse) chromatin thread.

One or more marrow samples were obtained from 43 subjects in the trial. In order to avoid bias in the interpretation of the morphological appearance of the marrow films 104 stained films (two from each patient and from patients not in the trial) were allotted numbers after the identification of the film had been concealed. These were studied after completion of the trial, and the degree of change (if any) in the myeloid and erythroid cells was scored separately as $0, \frac{1}{2}, 1$, or $2\left(0=\right.$ normal ; $\frac{1}{2}=$ possibly big metamyelocyte, some erythroid change ; $1=$ definite giant metamyelocytes, megaloblastic change in erythroid cells; $2=$ marked changes). Thus maximum score in a single film was 4 , and when the two smears from each case were totalled the maximum possible score was 8 . Subsequently the results on the duplicate slides were compared to assess whether scoring had been consistent. A total score of $3 \frac{1}{2}$ or more for the two films was accepted as indicating the presence of a megaloblastic form of haemopoiesis.

All marrow films were also stained for the presence of iron using Perls's Prussian-blue reaction.

\section{The Trial}

The purpose of the survey was explained to all pregnant women coming to the antenatal clinic for the first time before the 16th week of pregnancy. All but one of the 190 women asked to take part in the trial agreed to do so, and thereafter the women were allocated at random to one of the three groups. The tablets taken by the subjects in these three groups contained either ferrous fumarate (100 mg.), ferrous fumarate with $10 \mu \mathrm{g}$. folic acid, or lactose and were supplied by Glaxo Laboratories with green, blue, or red labels, the precise contents of each batch being unknown to us during the trial. Each subject was asked to take one tablet three times each day throughout pregnancy.

Blood for a blood count and for the estimation of serum $L$. casei activity was taken and after $15 \mathrm{~g}$. of oral histidine an eighthour urine sample was obtained for Figlu estimation. These observations were repeated at the 20th, 30th, 35th, and 39th weeks of pregnancy and finally on the 6th day after delivery.

Sternal-marrow aspirations were performed either when haemoglobin concentrations remained abnormally low or when inspection of the stained blood film suggested an increase in hypersegmented neutrophils. The enumeration of neutrophil lobes was time-consuming, and these values were not completed until some months after the end of the clinical trial. In addition a marrow sample was obtained from 16 subjects who appeared to be haematologically normal.

Studies were completed on 154 pregnant subjects, although all the samples could not be obtained in every subject. A further 35 women were withdrawn from the trial: 22 because they had moved out of the district; five because they were unable to tolerate the dose of histidine or were unable to collect a successful eight-hour urine sample; and eight because they aborted. Nine subjects receiving placebo tablets (lactose) required parenteral-iron therapy because of iron-deficiency anaemia, as did one patient receiving ferrous fumarate with added folic acid. In calculating mean values and in subsequent statistical analysis these 10 cases have been omitted.

The number of tablets taken each day was assessed by direct questioning, by asking all subjects to return a questionary after completion of the survey, and by noting the number of bottles (each containing 100 tablets) required by each patient.

\section{Results}

Haemoglobin Concentration and Packed-cell Volume.-The mean haemoglobin concentration and packed-cell volume fell to a similar extent in the three groups up to the 20th week of pregnancy (Table I). Thereafter these values continued to fall in the group receiving placebo tablets, and nine patients in this group required parenteral iron. At the end of pregnancy the

\begin{tabular}{|c|c|c|c|c|c|c|}
\hline \multirow{2}{*}{ Supplement } & \multicolumn{5}{|c|}{ Duration of Pregnancy (Weeks) } & \multirow{2}{*}{$\begin{array}{c}\text { Puer- } \\
\text { perium }\end{array}$} \\
\hline & -16 & 20 & 30 & 35 & 39 & \\
\hline Placebo (42) $\left\{\begin{array}{l}\text { Hb } \\
\text { P.C.V. }\end{array}\right.$ & $\begin{array}{l}12 \cdot 9 \\
39 \cdot 1\end{array}$ & $\begin{array}{l}12 \cdot 2 \\
37 \cdot 3\end{array}$ & $\begin{array}{l}11 \cdot 8 \\
36 \cdot 3\end{array}$ & $\begin{array}{l}11 \cdot 8 \\
36 \cdot 7\end{array}$ & $\begin{array}{l}12 \cdot 0 \\
36 \cdot 9\end{array}$ & $\begin{array}{l}12 \cdot 1 \\
37 \cdot 7\end{array}$ \\
\hline Iron (50) $\quad\left\{\begin{array}{l}\mathrm{Hb} \\
\text { P.C.V. }\end{array}\right.$ & $\begin{array}{l}12 \cdot 8 \\
38 \cdot 9\end{array}$ & $\begin{array}{l}12 \cdot 0 \\
36 \cdot 7\end{array}$ & $\begin{array}{l}12 \cdot 1 \\
36 \cdot 9\end{array}$ & $\begin{array}{l}12 \cdot 4 \\
37 \cdot 9\end{array}$ & $\begin{array}{l}13 \cdot 0 \\
39 \cdot 1\end{array}$ & $\begin{array}{l}13 \cdot 1 \\
40 \cdot 0\end{array}$ \\
\hline $\begin{array}{l}\text { Iron and folic } \\
\quad \text { acid (52) }\end{array}\left\{\begin{array}{l}\text { Hb } \\
\text { P.C.V. }\end{array}\right.$ & $\begin{array}{r}12 \cdot 9 \\
39 \cdot 0\end{array}$ & $\begin{array}{l}12 \cdot 0 \\
36 \cdot 7\end{array}$ & $\begin{array}{l}12 \cdot 1 \\
37 \cdot 7\end{array}$ & $\begin{array}{l}12 \cdot 3 \\
37 \cdot 7\end{array}$ & $\begin{array}{l}12 \cdot 7 \\
38 \cdot 5\end{array}$ & $\begin{array}{l}12.8 \\
39 \cdot 5\end{array}$ \\
\hline
\end{tabular}


mean haemoglobin concentration in the subjects having lactose only was $1 \mathrm{~g}$. $/ 100 \mathrm{ml}$. less than in the two iron-supplemented groups.

Neutrophil Changes.-(1) Average lobe index: In all three groups the average lobe index declined to a similar extent throughout pregnancy (Table II). (2) Hypersegmented neutrophils: When the percentage of neutrophils having five or more nuclear segments was compared striking differences were seen. The percentages of hypersegmented neutrophils in all the blood films throughout pregnancy are shown in Fig 1. After the

TABLE II.-Number of Nuclear Lobes in the Neutrophil Polymorphonuclear Leucocytes Expressed as the Average Lobe Index per Cell in the Three Groups

\begin{tabular}{|c|c|c|c|c|c|c|}
\hline \multirow{2}{*}{ Supplement } & \multicolumn{5}{|c|}{ Duration of Pregnancy (Weeks) } & \multirow{2}{*}{$\begin{array}{l}\text { Puer- } \\
\text { perium }\end{array}$} \\
\hline & -16 & 20 & 30 & 35 & 39 & \\
\hline $\begin{array}{l}\text { Placebo }(42) \quad \ldots \\
\text { Iron (50) } \\
\text { Iron and folic acid }(52)\end{array}$ & $\begin{array}{l}2 \cdot 3 \\
2 \cdot 4 \\
2 \cdot 3\end{array}$ & $\begin{array}{l}2 \cdot 2 \\
2 \cdot 3 \\
2 \cdot 2\end{array}$ & $\begin{array}{r}2 \cdot 1 \\
2 \cdot 2 \\
2 \cdot 1\end{array}$ & $\begin{array}{l}2 \cdot 1 \\
2 \cdot 2 \\
2 \cdot 1\end{array}$ & $\begin{array}{l}2 \cdot 1 \\
2 \cdot 1 \\
2 \cdot 1\end{array}$ & $\begin{array}{l}2 \cdot 0 \\
2 \cdot 0 \\
2 \cdot 0\end{array}$ \\
\hline
\end{tabular}

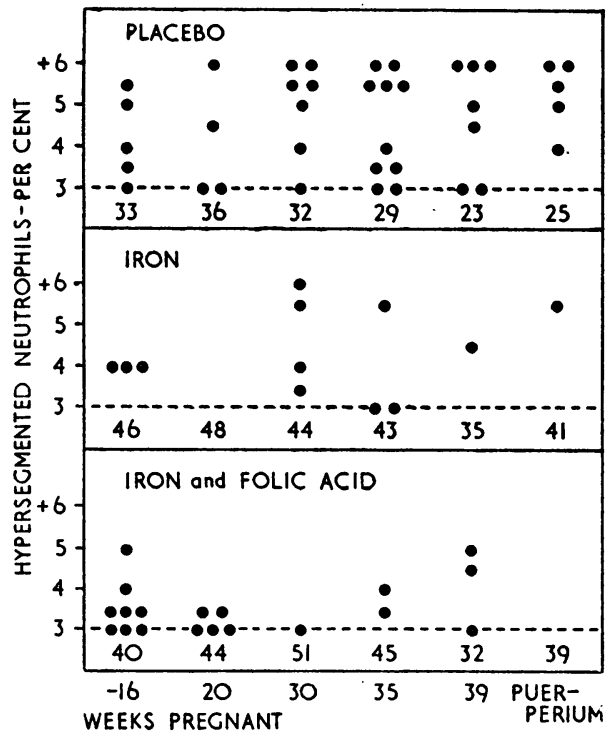

FIG. 1.-Proportion of hypersegmented neutrophil polymorphs - that is, with five or more nuclear segments-expressed as a percentage of 200 cells in the peripheral blood films of the pregnant subjects in the trial. The interrupted line denotes the upper limit $(3 \%)$ of hypersegmented forms in haematologically normal subjects. The numbers below the interrupted line are the numbers of pregnant women whose lobe counts were within the normal range at the particular periods of pregnancy; the black dots (O) the percentage of hypersegmented neutrophils in the remaining subjects.

30th week of pregnancy hypersegmented neutrophils in excess of $3 \%$ were found in 13 out of 42 subjects receiving only lactose (including three given parenteral iron), in 4 out of 50 subjects receiving only iron supplements, and in 2 out of 52 subjects receiving the iron and folic-acid supplements. The excess of five-lobed neutrophils in the group receiving lactose as compared with the two other groups was statistically significant at the $5 \%$ level.

Sternal-marrow Aspiration.-Marrow samples were obtained from 20 women taking lactose ; eight of these showed megaloblastic haemopoiesis. Ten marrow samples were taken from women receiving iron tablets, and three were megaloblastic. Thirteen marrow samples were obtained from women receiving the iron and folic-acid supplements, and four were megaloblastic.

Correlation between Marrow and Peripheral Blood Findings. -Examination of the sternal-marrow films showed a megaloblastic form of haemopoiesis in 15 subjects. Hypersegmented neutrophil polymorphs in increased numbers were present in
10 of these patients, but the neutrophil polymorphs were morphologically normal in the remaining five patients whose marrows showed megaloblastic haemopoiesis. In addition, an increased proportion of hypersegmented neutrophils was present in seven other patients whose marrows showed normoblastic haemopoiesis. All these patients had evidence of iron-deficiency anaemia with a reduced haemoglobin level and low mean corpuscular haemoglobin concentration. We were unable to find any correlation between the presence of hypersegmented neutrophils in increased numbers and the presence of giant metamyelocytes in the marrows in the patients whose marrow biopsies were judged to be normoblastic.

Marrow Iron Stores.-All the marrow samples were stained for iron using Perls's Prussian-blue method. Stainable iron was present in only 4 out of a total of 49 marrow samples. One of these four subjects had received iron tablets and the other three had had iron and folic-acid tablets.

Serum L. casei (Folate) Levels. - There was a decline in the mean serum $L$. casei levels throughout pregnancy (Fig. 2, Table III). The mean $L$. case $i$ levels were sustained at a higher level throughout pregnancy in the folic-acid-supplemented group and fell most markedly in the group receiving only lactose. Nevertheless, these differences did not prove to be

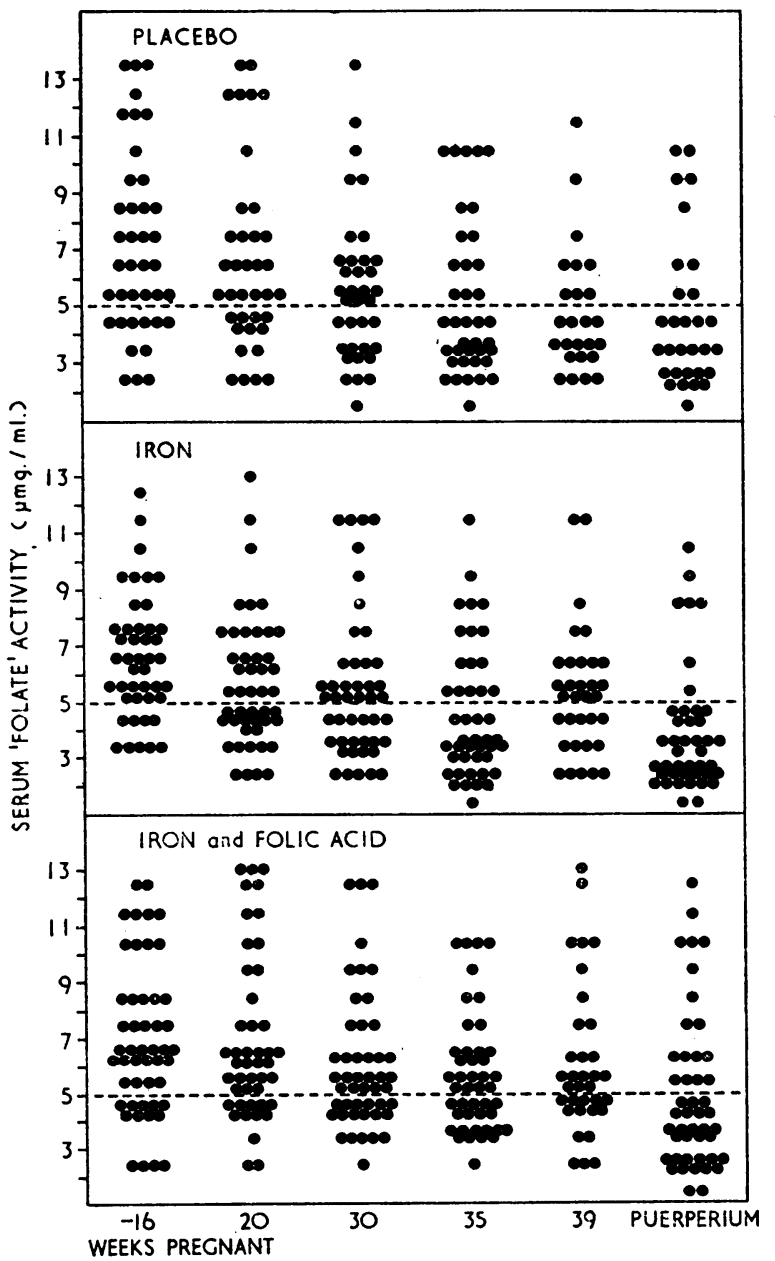

FIg. 2-Serum L. casei or folate activity throughout pregnancy in the subjects in the trial.

TABLB III-Mean Serum L. casei (Folate) Activity ( $\mu \mathrm{mg} . / \mathrm{ml}$ ) Throughout Pregnancy in the Three Groups

\begin{tabular}{|c|c|c|c|c|c|c|}
\hline \multirow{2}{*}{ Supplement } & \multicolumn{5}{|c|}{ Duration of Pregnancy (Weeks) } & \multirow{2}{*}{$\begin{array}{l}\text { Puer- } \\
\text { perium }\end{array}$} \\
\hline & -16 & 20 & 30 & 35 & 39 & \\
\hline $\begin{array}{l}\text { Placebo (42) } \quad \ldots \\
\text { Iron (50) } \\
\text { Iron and folic } \\
\text { acid }(52)\end{array}$ & $\begin{array}{l}7 \cdot 1 \\
6 \cdot 4 \\
6 \cdot 8\end{array}$ & $\begin{array}{l}6 \cdot 2 \\
5 \cdot 6 \\
6 \cdot 8\end{array}$ & $\begin{array}{l}5 \cdot 3 \\
5 \cdot 3 \\
5 \cdot 9\end{array}$ & $\begin{array}{l}4.9 \\
4.5 \\
5 \cdot 4\end{array}$ & $\begin{array}{l}4 \cdot 3 \\
5 \cdot 2 \\
5 \cdot 8\end{array}$ & $\begin{array}{l}4 \cdot 3 \\
3 \cdot 8 \\
4 \cdot 4\end{array}$ \\
\hline
\end{tabular}


statistically significant. The mean serum $L$. casei level in the 15 subjects who developed a megaloblastic form of haemopoiesis was $5.8,5.0,4.5,4.6,4.5$, and $3.5 \mu \mathrm{mg} . / \mathrm{ml}$. at $-16,20,30,35$, and 39 weeks of pregnancy and in the puerperium respectively.

Urinary Figlu Excretion.-There was a decline in the amount of Figlu appearing in the urine after a $15-\mathrm{g}$. dose of histidine as pregnancy approached term, and there were no obvious differences between the three groups (Fig. 3, Table IV). The mean urinary Figlu excretion in the 15 subjects who developed a megaloblastic form of haemopoiesis was $25.1,11.9,6.2,11.7$, 11.6 , and $9.7 \mathrm{mg}$. at $-16,20,30,35$, and 39 weeks of pregnancy and in the puerperium respectively.

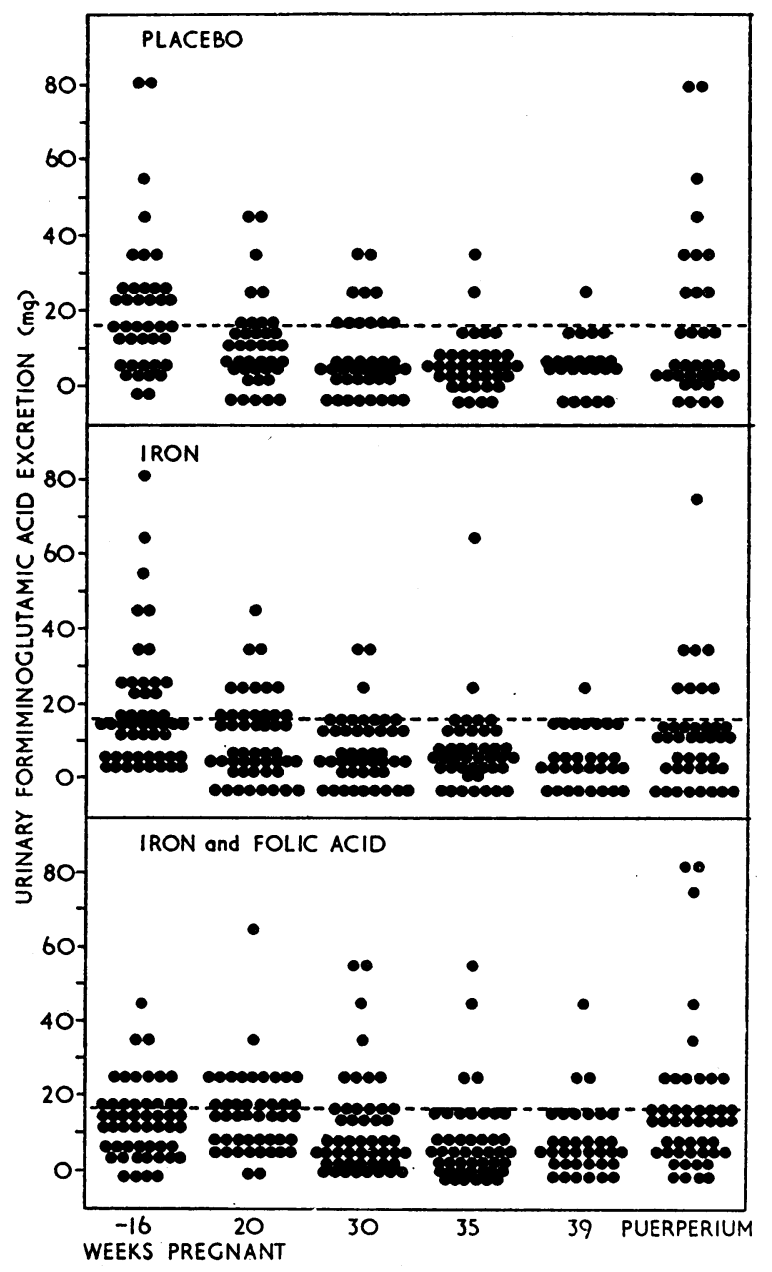

FIG. 3.-Urinary formiminoglutamic acid excretion after an oral dose of $15 \mathrm{~g}$. of histidine hydrochloride throughout pregnancy in the subjects in the trial.

TABLE IV.-Mean Urinary Excretion of Formiminoglutamic Acid (mg. in Eight Hours) After $15 \mathrm{~g}$. of Histidine Hydrochloride by Mouth Throughout Pregnancy in the Three Groups

\begin{tabular}{|c|c|c|c|c|c|c|}
\hline \multirow{2}{*}{ Supplement } & \multicolumn{5}{|c|}{ Duration of Pregnancy (Weeks) } & \multirow{2}{*}{$\begin{array}{l}\text { Puer- } \\
\text { perium }\end{array}$} \\
\hline & -16 & 20 & 30 & 35 & 39 & \\
\hline $\begin{array}{llr}\text { Placebo }(42) & \ldots & \\
\text { Iron (50) } \\
\text { Iron and folic acid (52) }\end{array}$ & $\begin{array}{l}38 \cdot 7 \\
20 \cdot 5 \\
14 \cdot 1\end{array}$ & $\begin{array}{l}12 \cdot 3 \\
14 \cdot 8 \\
14 \cdot 3\end{array}$ & $\begin{array}{r}9.0 \\
8.7 \\
12.1\end{array}$ & $\begin{array}{l}9 \cdot 4 \\
7 \cdot 6 \\
8 \cdot 8\end{array}$ & $\begin{array}{l}6.3 \\
6.0 \\
8.7\end{array}$ & $\begin{array}{l}19 \cdot 6 \\
13 \cdot 8 \\
17.3\end{array}$ \\
\hline
\end{tabular}

Number of Tablets Taken.-Sixty-three subjects returned a form after completion of the survey, which indicated that on an average 3.8 bottles had been finished. Direct questioning of 33 subjects while in hospital suggested that on the average they had taken tablets in 3.4 bottles. There were no differences between the three groups. On the average, therefore, the subjects in the survey took two out of the three prescribed tablets each day.
Further Data on Nine Subjects Initially Receiving the Placebo and who Required Parenteral-iron Therapy.-These subjects were presumably the most severely iron-depleted subjects in the group. Their mean haemoglobin concentration was 11.4 g./100 $\mathrm{ml}$. when first seen as compared with $12.9 \mathrm{~g}$. for the rest of the group. Throughout pregnancy the mean haemoglobin level declined to $10.2 \mathrm{~g}$. at the 30 th week and despite parenteral iron (500 mg.) only reached $11.8 \mathrm{~g}$. in the puerperium. The urinary Figlu was abnormally elevated in six of the nine subjects before the 16 th week $(19,35,47,86,100$, and $188 \mathrm{mg}$. respectively), with a mean excretion of $55 \mathrm{mg}$. for all nine subjects. The Figlu excretion declined to a very low level in the usual way in eight subjects but one subject who initially had a urinary excretion between 100 and $300 \mathrm{mg}$. maintained an abnormally elevated excretion throughout pregnancy. The mean $L$. casei levels before the 16 th week and at $20,30,35$, and 39 weeks and the puerperium were $6.8,4.9,4.8,5.3,4.0$, and $4.5 \mu \mathrm{mg} . / \mathrm{ml}$. respectively. Three subjects showed an increase of hypersegmented neutrophils. Five of the nine patients had a marrow aspiration performed and one of these had megaloblastic haemopoiesis.

Obstetric Complications.-There appeared to be no correlation between the incidence of infection of the urinary tract, antepartum or post-partum haemorrhage, threatened abortion, prematurity, or hypertension in any of the parameters we have studied. In particular, none of these complications was more frequent among subjects who had a low serum $L$. casei as compared with those who did not, or in subjects who had an increased proportion of hypersegmented neutrophils, or in subjects who had elevated urinary Figlu excretion. The incidence of these complications was no more frequent in those receiving the placebo as compared with the iron and the iron-plus-folate supplemented groups.

\section{Discussion}

\section{Selection of Dose of Folic Acid}

Haematological responses in folic-acid-" deficient" megaloblastic anaemias have been obtained with amounts of folic acid varying from 5 to $25 \mu \mathrm{g}$. daily (Sheehy, Rubini, Perez-Santiago, Santini, and Haddock, 1961 ; Druskin, Wallen, and Bonagura, 1962 ; Velez, Ghitis, Pradilla, and Vitale, 1963) and almost all patients in the absence of abnormal demand for the vitamin respond to doses of $50 \mu \mathrm{g}$. each day. Abnormal excretion of Figlu can often be corrected with doses of folic acid of 10-20 $\mu \mathrm{g}$. daily (unpublished observations), and it has been claimed that the appearance of this substance in the urine, when the diet is restricted, can be prevented by a supplement of $5 \mu \mathrm{g}$. daily (Knowles, Prankerd, and Westall, 1961). Herbert (1964) found that a folic-acid intake of $25 \mu \mathrm{g}$. daily, when added to an apparently folate-free diet, was insufficient to sustain a normal serum "folate" level whereas a supplement of $50 \mu \mathrm{g}$. daily proved adequate.

Observations on the amount of folic acid supplied by a normal diet are difficult to interpret because of the presence of non-folate material supporting the growth of the microbiological-assay organisms and because of uncertainty about the availability to man of the various forms of folate present in food (Butterworth, Santini, and Frommeyer, 1963). Thus the daily folate requirement is probably less than $50 \mu \mathrm{g}$. daily and the amount likely to be present in the diet is uncertain. On this basis it was decided to give $30 \mu \mathrm{g}$. of folic acid daily.

\section{Effect of Folic-acid Supplement in Pregnancy}

The supplement of $20 \mu \mathrm{g}$. of folic acid actually taken by subjects in this survey each day was inadequate in preventing the onset of a megaloblastic form of haemopoiesis, and at least 
four patients with a megaloblastic form of haemopoiesis were found among 51 subjects in the folic-acid-supplemented group.

Assay of serum L. casei levels throughout pregnancy showed that the mean levels in the group taking both iron and folic acid were maintained at a higher level throughout pregnancy than was the case in the other two groups. Nevertheless the wide scatter of values was such that the differences were not statistically significant. Nor was there any other evidence that this small dose of folic acid produced any benefit beyond that present in the group taking the iron supplement alone.

\section{Effect of Iron Deficiency}

Absence of haemosiderin from an adequate marrow specimen indicates iron depletion (Bothwell and Finch, 1962). Iron was absent from the marrow in 45 out of 49 samples, indicating that iron deficiency was almost the rule in the present subjects. However, the effect of iron deficiency was most pronounced in the women receiving only lactose, and the mean haemoglobin concentration in this group was $1 \mathrm{~g}$. less than in the ironsupplemented groups at the end of pregnancy.

The relation between iron deficiency and a megaloblastic form of haemopoiesis is a relatively unexplored field. The observations of Tasker (1959) show that where lack of iron is the limiting factor in haemopoiesis the morphological changes in marrow and blood will be those of iron deficiency. When adequate amounts of iron are supplied the morphological changes may then reflect the presence of other coexisting deficiencies such as that of folic acid. Thus the form of haemopoiesis in the marrow may become megaloblastic and macrocytes may be delivered to the peripheral blood. Iron deficiency therefore may conceal the morphological evidence of a megaloblastic anaemia.

The observations in this study suggest that iron deficiency has a more fundamental role in relation to megaloblastic anaemia than merely concealing its presence and that iron deficiency plays an important part in producing folic-acid deficiency in the first instance. Thus the highest incidence of megaloblastic anaemia was found in the most markedly iron-depleted group.

Even more striking was the presence of an excess of hypersegmented neutrophil in $24 \%$ of the patients receiving lactose as compared with only $6 \%$ among subjects in the other groups. Hypersegmented neutrophils in increased numbers suggest the presence of megaloblastic haemopoiesis.

Further, the serum $L$. case $i$ levels showed the greatest decline in the group receiving lactose: a fall from a mean of $5.3 \mu \mathrm{mg}$./ $\mathrm{ml}$. at 30 weeks to $4.3 \mu \mathrm{mg}$. $/ \mathrm{ml}$. at 39 weeks. No such fall was evident in the iron-supplemented groups.

Finally, six of nine subjects who required parenteral iron, and who were presumably the most severely iron-deficient subjects in the group taking lactose only, showed the highest Figlu excretion when first seen. An elevated Figlu excretion has been noted in simple iron deficiency (Chanarin, Bennett, and Berry, 1962).

Thus the evidence suggests that iron deficiency adversely affected the folic-acid status of the group not given an iron supplement, leading to a high proportion of hypersegmented neutrophils in stained blood films, to a high incidence of megaloblastic anaemia, and to a decline in the serum $L$. case $i$ (folate) levels.

\section{Significance of Hypersegmented Neutrophils}

The changes in the neutrophil polymorphonuclear leucocytes may be assessed by either noting the variation in average lobe index, a method favoured by Herbert (1964), or noting the change in the proportion of cells having five or more lobes in the nucleus-“" hypersegmented forms"-3\% being the upper limit for such cells in normal subjects. It is easier to count hypersegmented forms only than to enumerate with accuracy the numbers of lobes in all cells, because the lobes overlap. Further, counting of only hypersegmented forms overcomes the problem of the normal shift to the left that occurs in pregnancy, a factor that reduces the value of the average lobe index.

An increased proportion of hypersegmented neutrophils was found at some stage in 19 of the subjects in this study, and marrow aspirations were obtained in 17 of these. All these subjects had evidence of iron deficiency, and the marrow showed that 10 of them were also megaloblastic with prominent giant metamyelocytes.

The marrows in the remaining seven subjects who had an increased proportion of hypersegmented neutrophils showed only the changes of iron deficiency. In particular giant metamyelocytes were generally no more prominent in these marrows than in other normoblastic marrows in this study. There is therefore no evidence for regarding the neutrophil changes in these seven patients as due to interference with folate metabolism. This still remains a possibility, and, in particular, we have repeated the marrow aspiration in only one of these subjects after parenteral-iron therapy. This marrow remained normoblastic.

Nevertheless, although not all patients with an increased proportion of hypersegmented neutrophils were found to have a megaloblastic form of haemopoiesis, the presence of these cells in peripheral blood films was the most valuable single aid in the diagnosis of megaloblastic anaemia in pregnancy. The other important features suggesting megaloblastic haemopoiesis were the persistence of anaemia, usually of minor degree, despite iron therapy (Giles and Shuttleworth, 1958) and, less frequently, the presence of occasional macrocytes in the peripheral blood film.

\section{Incidence of Megaloblastic Anaemia}

Giles and Shuttleworth (1958) recorded an incidence of megaloblastic anaemia of $2.8 \%$ among their antenatal population, and many other series have noted an equally high incidence of this form of haemopoiesis since that time. Of 154 pregnant subjects completing the survey, $15(9.7 \%)$ were found to be megaloblastic, and the incidence rose to $16.6 \%$ in the group not given supplemental iron. This unusually high incidence is related to the high proportion of sternal-marrow aspirations that were carried out. Lowenstein, Brunton, Cooper, Milad, and Hsieh (1963) reported megaloblastic marrow changes in 16 out of 62 patients who did not receive any form of supplement ; an incidence of $26 \%$. Hansen (1964) found morphological changes in the marrow in one-third of pregnant women.

The recording of a high incidence of megaloblastic haemopoiesis always raises the suspicion that too much is being deduced from minor changes in the marrow. In the present series only unequivocal changes in morphology were regarded as significant, and minor changes of macronormoblastic type, so common in pregnancy, were ignored.

\section{“ Unexpected" Megaloblastic Haemopoiesis}

The presence of hypersegmented neutrophils in increased amount or persistent anaemia was the indication for a marrow aspiration in 11 of the 15 women in whom a diagnosis of megaloblastic anaemia was made. A marrow aspiration was carried out on another subject because inspection of the blood film suggested an increase in five-lobed neutrophils, although a subsequent count failed to confirm this impression. This marrow, too, showed megaloblastic haemopoiesis. The remaining three patients with megaloblastic marrows were among a group of 16 women on whom marrow aspirations were carried out in order to obtain controls. At that time examination of the peripheral blood was normal. In the present state of our 
knowledge it does not seem possible to have anticipated this diagnosis from either study of the peripheral blood or from the results of other tests such as serum $L$. case $i$ levels. In none of these patients was the serum $L$. case $i$ level very low, and the lowest levels reached at the end of pregnancy were 4.0, 4.0, 4.5 , and $6.5 \mu \mathrm{mg} . / \mathrm{ml}$.

\section{Value of the Ancillary Tests in the Diagnosis of Megaloblastic Anaemia}

Our experience is that neither the estimation of the urinary Figlu excretion nor of the serum $L$. casei activity is of value in the diagnosis of megaloblastic anaemia whether associated with pregnancy or in non-pregnant individuals (Chanarin, 1964). This diagnosis remains a morphological one. On the other hand, Hansen (1954) found the estimation of whole-blood folic acid of value in diagnosing megaloblastic anaemia in pregnancy, and Ball and Giles (1964) report favourably on the serum $L$. casei activity, particularly the assay of the so-called "labile-fraction." The declining $L$. casei levels throughout pregnancy confirm the observations of Solomons, Lee, Wasserman, and Malkin (1962) and probably indicate a high incidence of subclinical folic acid in pregnancy. The results are basically the same as those found using the rate of clearance from the blood of intravenously injected folic acid as the index of folicacid deficiency (Chanarin, MacGibbon, O'Sullivan, and Mollin, 1959), indicating that about $60 \%$ of pregnant subjects are unable to meet the demands in pregnancy for increased amounts of folic acid.

\section{Conclusion}

Iron deficiency of greater or less degree was the rule in the pregnant subjects studied and was most marked in patients not receiving oral iron supplements.

The effect of iron deficiency on the folic-acid status in pregnancy is twofold. First, it may conceal the morphological evidence of a megaloblastic anaemia. Second, iron deficiency appears to be an important factor in the aetiology of the folicacid-deficiency state. In this respect the pathogenesis of megaloblastic anaemia in pregnancy has much in common with megaloblastic anaemia in post-gastrectomy patients. In both there is an association of iron deficiency and megaloblastic anaemia, and it is likely that, in both, iron deficiency, by producing an additional stress of a folate metabolism, plays an important part in converting a subclinical folic-acid or vitamin$B_{12}$ deficiency into an overt megaloblastic anaemia. Prophylactic-iron therapy in pregnancy therefore not only prevents iron deficiency but also reduces the incidence of megaloblastic anaemia.

A daily supplement of $20 \mu \mathrm{g}$. of folic acid was inadequate in influencing the incidence of megaloblastic anaemia, and further work is required to determine the amount of folic acid needed to enable a normal pregnant subject to meet the increased physiological demands for this vitamin.

\section{Summary}

Pregnant women coming to the antenatal clinic before the $16 \mathrm{th}$ week of pregnancy were allocated at random to one of three groups receiving throughout pregnancy lactose, $100 \mathrm{mg}$. of ferrous fumarate, or $100 \mathrm{mg}$. of ferrous fumarate with $10 \mu \mathrm{g}$. folic acid as tablets three times a day. The group receiving only lactose showed the highest incidence of iron-deficiency anaemia, the greatest proportion of hypersegmented neutrophils in peripheral blood films, the lowest serum $L$. casei values, and, finally, the highest incidence of megaloblastic anaemia.

Some cases of megaloblastic anaemia also occurred in the group receiving the small folic-acid supplement.

The data were interpreted as indicating that iron deficiency produced additional stress on folate metabolism in pregnancy and hence produced an increased incidence of megaloblastic anaemia. The frequency of megaloblastic anaemia in pregnancy can be reduced by adequate iron supplementation, but a larger folic-acid supplement that $20 \mu \mathrm{g}$. each day would be required to eliminate this form of anaemia.

We wish to express our indebtedness to Glaxo Research Ltd. for supplying the tablets used in the trial, and in particular to Dr. T. Binns and Mr. H. G. Gresley-Grey for their advice and statistical analysis of the data ; to Dr. Maureen Booth for assistance with the microbiological and chemical estimations; and to Professor Ian MacGillivray for permitting us to study the pregnant subjects under his care.

\section{REFERENCES}

Baker, H., Herbert, V., Frank, O., Pasher, I., Hutner, S. H., Wasserman, L. R., and Sobotka, H. (1959). Clin. Chem., 5, 275.

Ball, E. W., and Giles, C. (1964). 7. clin. Path., 17, 165.

Bothwell, T. H., and Finch, C. A. (1962). Iron Metabolism. Churchill, London.

Butterworth, C. E., Santini, R., and Frommeyer, W. B. (1963). F. clin. Invest., 42, 1929.

Chanarin, I. (1964). Proc. roy. Soc. Med., 57, 384.

- and Bennett, M. C. (1962). Brit. med. F., 1, 27.

- and Berry. V. (1962). F. clin. Path., 15, 269.

and Berry, V. (1964). Ibid., 17, 111.

MacGibbon, B. M., O'Sullivan, W. J., and Mollin, D. L. (1959). Lancet, 2, 634.

- Rothman, D., and Watson-Williams, E. J. (1963). Ibid., 1, 1068.

Clark, J. R. (1952). Edinb. med. 7., 59, 274.

Druskin, M. S., Wallen, M. H., and Bonagura, L. (1962). New Engl. 7. Med., 267, 483 .

Forshaw, J., Moorhouse, E. H., and Harwood, L. (1964). Lancet, 1, 1004

Giles, C., and Shuttleworth, E. M. (1958). Ibid., 2, 1341.

Hansen, H. A. (1964). On the Diagnosis of Folic Acid Deficiency. Almquist and Wiksell, Stockholm.

Herbert, V. (1964). Proc. roy. Soc. Med., 57, 377.

Hibbard, B. M., and Hibbard, E. D. (1963). Brit. med. F., 2, 1430.

Hourihane, B., Coyle, C. V., and Drury, M. I. (1960). F. Irish med. Ass., $47,1$.

Knowles, J. P., Prankerd, T. A. J., and Westall, R. G. (1961). f. Physiol. (Lond.), 157, 24P.

Lowenstein, L., Brunton, L., Cooper, B., Milad, A., and Hsieh, Y. S. (1963). Proceedings of Ninth Congress of the European Society of Haematology, Lisbon.

Sheehy, T. W., Rubini, M. E., Perez-Santiago, E., Santini, R., and Haddock, J.' (1961). Blood, 18, 623.

Solomons, E., Lee, S. L., Wasserman, M., and Malkin, J. (1962). J. Obstet. Gynaec. Brit. Cwlth, 69, 724.

Tasker, P. W. G. (1959). Trans. roy. Soc. trop. Med. Hyg., 53, 291.

Toepfer, E. W., Zook, E. G., Orr, M. L., and Richardson, L. R. (1951). Folic Acid Content of Foods. Agricultural Handbook No. 29, U.S. Dept. of Agriculture, Washington, D.C.

Varadi, S. (1964). Lancet, 1, 1331.

Velez, H., Ghitis, J., Pradilla, A., and Vitale, J. J. (1963). Amer. ¥. clin. Nutr., 12, 54 .

Waters, A. H., and Mollin, D. L. (1961). 7. clin. Path., 14, 335. 